\title{
SOBRE LUTOS E LUTAS: VIOLÂNGIA DE ESTADO, HUMANIDADE E MORTE EM DOIS CONTEXTOS ETNOGRÁFIGOS
}

Liliana Sanjurjo
Gabriel Feltran

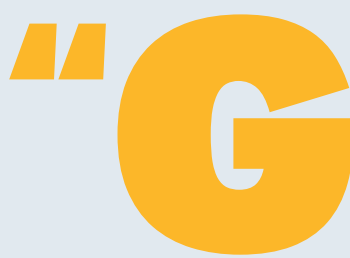

uerra às drogas", "guerra ao crime", "guerra contra a subversão", "guerra ao terror". Palavras de ordem na contemporaneidade. A lógica guerreira da militarização vem pautando as políticas de segurança nacionale, mais recentemente, as políticas de segurança pública em diversos países do mundo (1). Especialmente no contexto latino-americano, tanto no passado ditatorial recente quanto na presente forma democrática, observa-se como distintos governos, por meio dos sujeitos e instituições que os constituem, colocam em ação enunciados valorativos a fim de justificar, sobretudo moralmente, as políticas estatais de segurança e os atos repressivos perpetrados contra aqueles categorizados como seus "inimigos internos". A política é a cada dia mais guerreira, a fronteira que define o inimigo é cada vez mais moral e ele está cada vez mais próximo. O conflito precisa ser administrado.

Compreendendo governo como uma esfera que reivindica os sentidos - existenciais, políticos e morais - que justificam a vida e a morte de sujeitos, individuais ou coletivos (2), buscamos analisar aqui como são atualizados os dispositivos de gestão da vida e, a partir deles, da ordem social que se construía em nossos contextos etnográficos, ambos muito marcados pela morte violenta. Gestão, portanto, que tem o assassinato como possibilidade mais ou menos presente e que culmina em processos de categorização, hierarquização e construção de fronteiras sociais (3). Nesse sentido, em consonância com as reflexōes de Butler (4) sobre a questão da violência, do luto e do reconhecimento da vida, problematizamos as circunstâncias, mas sobretudo as perspectivas, em que certas vidas são lamentadas, choradas e dignas de luto em público, enquanto outras não o são. A estas últimas vidas a comunidade nacional oferece o silêncio, ora porque são entendidas como animando os corpos que devem tombar numa "guerra justa" (eram terroristas, delinquentes, subversivos, traficantes, do crime organizado); ora porque compreendidas como externas ao sentido de pertencimento a qualquer humanidade comum (eram monstros, veja o que fizeram, nem animais o fariam).

Distintas formas de discurso (do jurídico ao científico, do jornalístico ao acadêmico) produzem o "excluído", os corpos deslocados da humanidade, considerados então pelo poder como desimportantes, supérfluos, as vidas que deveriam ser corrigidas ou que não mereceriam ser vividas. O lugar desse "excluído" seria de silêncio, que, concretamente, se realiza na sensação de injustiça por não poder existir socialmente, não gozar de qualquer interesse por parte do mundo, por habitar uma vida condenada à morte silenciosa. Este artigo quer analisar contextualmente as consequências políticas manifestas nas concepçôes normativas do humano que suspendem a validade da vida de sujeitos e grupos, produzindo uma multidão de "vidas sem valor" cujo estatuto político se encontra substantivamente suspenso, o que por vezes é acompanhado da perda do estatuto legal.

Partimos da experiência etnográfica específica em situações nas quais o Estado provoca a morte de seus "inimigos internos", para refletir sobre as fronteiras da noção de humano, bem como sobre seus significados políticos contemporâneos. Por um lado, tomamos como objeto um estudo sobre desaparecimento forçado, violência e política no contexto da última ditadura militar argentina e, por outro, uma etnografia sobre crime, violência e política em São Paulo (5). Por meio desse deslocamento etnográfico temporal e espacial - passado ditatorial argentino e presente da forma democrática brasileira -, esboçamos uma crítica que situa a violência de Estado contemporânea não como um desvio, mas como um instrumento chave para governar. O recorte moral do conjunto da população nos termos da guerra do bem contra o mal favorece a implementação de projetos político-econômicos específicos, mas se faz centralmente em nome da segurança pública ou segurança nacional.

Por um lado, analisamos a construção pública e conjuntural das grades de inteligibilidade que permitem a justificação de medidas letais, legais ou ilegais de "combate ao crime", "guerra às drogas", "luta contra a subversão", "defesa nacional". Por outro lado, verificamos as estratégias empreendidas por atores sociais incriminados para reagir à violência de Estado, tornar visíveis seus mortos e construir a sua posição pública como sujeitos legítimos de participação no espaço político ou, quando não, como sujeitos aptos a disputar o poder. Colocamos assim em diálogo as nossas etnografias para questionar a adjetivação dicotômica das violências (violência criminal, violência política), colocando-as em relação. Problematizamos a diferença de lugares de locução ocupados por familiares de desaparecidos políticos e por residentes das periferias da cidade, perante a violência sofrida. Verificamos que seus modos de reivindicar o direito à vida de seus semelhantes são submetidos a condiçôes de legitimação discursiva completamente diferentes. Que suas estratégias e crenças são, por isso, fundamentalmente distintas. Recortes na distribuição efetiva de "direitos" aparecem, então, condicionando o direito ao estatuto de locução pública, garantia de existência política, sinônimo de humanidade. Essas condiçōes de locução nos levam, então, a uma reflexão sobre o Estado e as formas de uso contemporâneo da violência estatal, realizada na segunda parte do texto. Os contrastes entre os contextos etnográficos em que estudamos essas questōes, apresentadas em linhas gerais a seguir, funcionam aqui mais para elaborar nosso próprio ponto de observação das relaçōes entre política e violência, do que para construir nossos objetos de estudo. Ditadura argentina e democracia brasileira serão, assim, 
representações a partir das quais se pode ensaiar uma reflexão crítica sobre as relações entre política e violência.

\section{VIOLÊNCIA DE ESTADO NA DITADURA ARGENTINA: DA LUTA PELO LUTO E PELA MEMÓRIA Foi pela violência perpetrada contra a po-} pulação civil que a última ditadura militar argentina (1976-1983) se tornaria conhecida. Dentre os métodos empregados para a imposição do terror, destaca-se a política de desaparecimento forçado daqueles definidos pelas autoridades como "terroristas", "delinquentes subversivos" e "inimigos da nação". As autoridades militares justificariam o golpe de Estado alegando que as forças armadas eram a única instituição capaz de "restaurar" os "verdadeiros valores da nação" e a cultura "ocidental e cristã". Os militares se apresentavam assim como combatentes de uma "guerra" travada "em nome de Deus", pela "defesa nacional" contra o "beligerante inimigo subversivo" e o "ateísmo marxista" (6).

Combinando discurso religioso a metáforas do parentesco, da guerra e da biologia para fundamentar a repressão, a "subversão" emergia na retórica da ditadura como "câncer" que deveria ser eliminado para não "contaminar" o "organismo nacional" (7). Além do mais, interpretando a "guerra contra a subversão" no marco da Doutrina de Segurança Nacional junto ao conceito de "guerra total" da doutrina contrainsurgente francesa, o discurso militar embaralhou as fronteiras que distinguiam o nacional do forâneo, ao passo que o conflito era definido em termos de uma guerra interna. Da perspectiva militar, tratou-se de uma "guerra justa", porém uma "guerra irregular" cujo signo distintivo teria sido a "imprecisão". Atos atrozes continuariam sendo assim justificados como sequelas, excessos, imprecisões ou equívocos (fatos supostamente inevitáveis às guerras) cometidos no contexto de uma ação legítima.

Fica evidente como, no contexto ditatorial, "subversão" foi a categoria englobante utilizada para delimitar as fronteiras de pertencimento à nação. Na conjuntura de então, marcada pelo capitalismo industrial e pela Guerra Fria, momento em que a polarização capitalismo X socialismo se impunha como conflito predominante, a figura do "delinquente subversivo" surgia como identidade dissonante da ordem social. Nessa operatória, o governo ditatorial criminalizava a oposição política, produzindo uma nova categoria de pessoa, os detenidos-desaparecidos, que, deslocados da humanidade porque concebidos como ameaçando os valores mais centrais da vida humana, eram condenados à morte silenciosa; vidas proibidas de existir para a preservação dos princípios da dignidade humana (a família, a tradição, a ordem, a religião), mortes por isso destituídas de identidade (8) e privadas do direito ao luto. Encarcerados em prisões clandestinas, os desaparecidos eram deslocados da vida social, perdendo o seu estatuto político e legal. Excluídos dos sistemas de inscrição da morte (cadáveres sem nome e sem história) (9), os desaparecidos eram deixados de fora do relato da nação, da comunidade política, apostando na impossibilidade da memória pela ausência do corpo (10).

Contudo, enquanto a ditadura buscava negar a existência dos desaparecidos, Madres de Plaza de Mayo e outros coletivos de familiares das vítimas se organizavam para mostrar que os desaparecidos tinham um rosto, um nome e uma história. Esses coletivos emergem na cena pública colocando suas demandas por "Memória, Verdade e Justiça” em linguagem de parentesco e de direitos humanos. Após décadas de incessante ativismo, os familiares de desaparecidos (e os próprios desaparecidos) marcam o seu lugar na vida política do país e as violações cometidas durante a ditadura dificilmente encontram respaldo social, ao passo que o evento crítico do desaparecimento forçado afirma-se como acontecimento político nacional (11). Observa-se ainda um processo de luto permanente pelos “30 mil detenidos-desaparecidos" e de reelaboração de sua memória na esfera pública, questão central que motivou a etnografia realizada por Liliana Sanjurjo; ou seja, compreender os processos que levariam os desaparecidos e as memórias da ditadura a ganhar tamanha repercussão social na Argentina contemporânea.

Cabe salientar que foi por meio de uma série de disputas políticas, simbólicas e jurídicas, na qual se encontram empenhados há mais de 30 anos, que esses coletivos de familiares foram adquirindo legitimidade social, consolidando publicamente um conjunto de representações sobre o passado ditatorial. Puderam assim converter (e pode-se dizer com eficácia) o estigma imposto às vítimas e seus familiares durante a ditadura em capital político no período democrático. A análise da trajetória de mobilização desses familiares e de significação da categoria detenidos-desaparecidos (12) - cujo percurso parte da negação de sua existência e culmina na sua reivindicação como grupo portador de um projeto político - revela como diferentes conjunturas históricas possibilitam, por um lado, que determinados agentes possam se construir como sujeitos legítimos de participação no espaço político e, por outro lado, que novos sentidos sejam atribuídos ao passado de violência.

Se durante a década de 1980 os familiares buscaram despolitizar a questão dos desaparecidos (13), atualmente se empenham precisamente em demonstrar o que faziam as vítimas politicamente para que fossem transformadas em alvo da repressão. $\mathrm{Ou}$ melhor, se no período de transição democrática as histórias de militância dos desaparecidos se viram silenciadas, esse silêncio deve ser lido em face a um contexto de alta adesão aos discursos que justificavam a violência letal. Para não integrar a alteridade negativa da ditadura(subversão), a denúncia da repressão perderia o seu contorno político-ideológico, dando lugar à construção de uma narrativa humanitária que convertia os desaparecidos em "vítimas de graves violações aos direitos humanos". 
Foi somente na segunda metade da década de 1990 que a memória dos desaparecidos começaria a ser definida em termos políticos, sendo agora reconhecidos como seres produtores de política (militantes populares, socialistas, revolucionários), assassinados pelos projetos políticos que encarnavam. Contemporaneamente, haveria ainda uma vontade de categorização (genocídio por razões políticas, terrorismo de Estado), que se articula no campo jurídico com a produção de um discurso de verdade (14). A argumentação se dirige então a comprovar que o Estado teria executado um plano sistemático de tortura e extermínio contra um grupo específico da população nacional, definido previamente segundo critérios políticos.

Por último, vale salientar que esse processo de crescente politização do relato da ditadura se dá numa conjuntura de crise da política neoliberal menemista - caracterizada pelo desemprego, precarização do trabalho e dos serviços de proteção social e, o mais importante, quando a violência de Estado já tem como foco prioritário outros grupos criminalizados (os pobres). Essa nova conjuntura, bem como o lugar social ocupado pelos coletivos de familiares de desaparecidos - constituídos, de uma maneira geral, por setores médios que, desde o princípio, já contavam com o capital social necessário para articular açōes no plano nacional e internacional -, parecem assim marcar uma diferença fundamental para a construção de sua posição pública como sujeitos legítimos de participação no espaço político, garantindo o direito ao estatuto de locução pública. Ao gozarem de existência política, puderam reagir à violência de Estado, tornar visíveis seus mortos, bem como responsabilizar penalmente os agentes do Estado implicados na repressão.

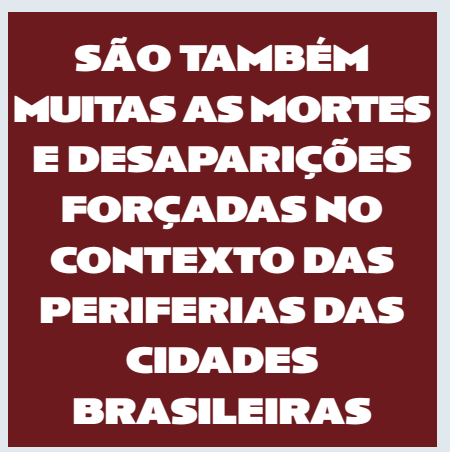

estudadas nessa etnografia não tiveram seguimento jurídico e foram recebidas, publicamente, com indiferença ou silêncio. Os poucos que tentavam traduzir essas mortes em luta, militantes de direitos humanos, eram logo acusados de "defender bandido". Direitos humanos para humanos direitos! Direitos humanos para bandidos? Ambas as violências - tanto a remetida aos corpos de jovens favelados que tombavam pela polícia ou seus pares, quanto a que se dirige à fala de militantes que os representariam (15) - foram predominantemente legítimas, nos meios públicos e em muitas famílias de periferia.

A surpresa dessa etnografia, no entanto, foi constatar que, conforme corria a pesquisa de campo nos anos 2000, eram cada vez mais raros os homicídios de jovens nas favelas de São Paulo. Nos anos 2000, o Primeiro Comando da Capital (PCC) implementava um sistema de justiça em todos os presídios e favelas, interconectado, que, em 2011, havia reduzido os homicídios nesses lugares em dez vezes. No conjunto da cidade, a queda foi de mais de $70 \%$ das mortes por armas de fogo, embora os latrocínios subissem no período. A queda dos assassinatos nas periferias de São Paulo, durante os anos 2000, não tinha como causa decisiva a redução das atividades criminais, mas seu oposto, a muito maior capilaridade da facção criminal, que instrumentalizava as políticas repressivas em curso, sobretudo o encarceramento massivo(16). O PCC passava a intermediar inúmeras situações de conflito local, em favelas e periferias, tendo por mote central evitar o homicídio de jovens e a interdição de vendetas entre eles, de modo a pacificar os mercados que regulava (drogas, carros roubados, assaltos, entre outros). O sistema foi bem sucedido, já está bem descrito na bibliografia (17). De um lado, morrem menos de um décimo dos jovens que morriam dez anos

VIOLÊNCIA DE ESTADO NA "DEMOCRACIA BRASILEIRA": MORTOS SEM LUTO, LUTA SEM VIRTUDE São também muitas as mortes e desaparições forçadas no contexto das periferias das cidades brasileiras, em período "democrático". Em São Paulo, a questão central que mobilizou a etnografia conduzida por Gabriel Feltran, no distrito de Sapopemba, remetia ao silêncio público em torno dos homicídios de adolescentes e jovens nas favelas, nos anos 1990 e início dos anos 2000. Embora pesquisando regiōes muito marcadas pela mobilização de movimentos populares - por saúde, moradia, transporte, educação - a temática da morte violenta de milhares de jovens, muitos deles trabalhadores de mercados ilegais como o da droga ou do roubo de carros, parecia não causar comoção aos movimentos sociais de trabalhadores do período. Restavam apenas as páginas policiais para publicizá-las. Os anos de etnografia foram tempos em que se solicitou nas rádios e televisões, nos comentários de notícias pela internet, progressivamente, e cada vez mais, que a repressão contra os pobres e seus territórios se radicalizasse: era preciso combater o crime que brotava de favelas e periferias. A justificação dessa premissa é moral, não precisa de argumentos. As denúncias de homicídios antes, nas periferias de São Paulo; de outro, o "crime" - e não um movimento com virtudes democráticas - parece ser o ator central de regulação da vida e da morte nas periferias. Situar-se politicamente frente a essa constatação leva a um paradoxo. Propõe-se a chave interpretativa de coexistência de regimes normativos nesses territórios, seguindo a hipótese de Machado da Silva (18). Crime e Estado compõem ali ordens legítimas que, em suas tensões e acomodações, produzem um dispositivo de ordem urbana composto entre políticas estatais e criminais, responsável hoje pela especificidade paulista na questão da "segurança pública". Todos os dados quantitativos elencados na bibliografia, bem como o cenário cíclico de tensões entre esses regimes normativos, em 2001, 2006 e 2012, corroboram esta hipótese analítica, hoje legítima na bibliografia.

Se um favelado é assassinado, essa morte não será investigada pelo Estado, não se montará um inquérito judicial. O PCC vai, entretanto, intermediar debates locais sobre o caso, com minúcia, para conhecer os fatos e as versões, para julgar os culpados, e no limite para implementar a justiça. Se um branco é morto em um assalto, não se aplica a ele a justiça do PCC, ela o ignora. O Estado cuidará 
do caso. Há uma fronteira entre esses dois regimes que define, entre outras coisas, o que é um homicídio em cada perspectiva e, portanto, os limites do humano em cada um dos regimes. O desenvolvimento histórico dessa fronteira não é infenso a tensōes, evidentemente. Em São Paulo, e em outras periferias urbanas brasileiras, o emprego rotineiro da violência ilegal como modo de arbítrio dos conflitos sociais que condicionam essas tensōes, tanto pelo "mundo do crime", quanto pelo Estado, indica a dimensão mais constitutivamente arraigada da violência no funcionamento democrático brasileiro.

\section{SOBRE LUTOS E LUTAS: DA DISTRIBUIÇÃO DESIGUAL DO RECONHE-}

CIMENTO DA VIDA Já não é surpreendente que o recurso à violência institucional, que se julgava próprio das ditaduras militares - tanto a violência massivamente aplicada a populaçōes consideradas ameaçadoras, quanto seletivamente voltada às vozes dissonantes - seja também instrumento fundamental da forma de governo contemporaneamente conhecida como democracia (19). Diferentes trabalhos vêm demonstrando a presença da chamada "violência política" nas democracias, seja na construção ativa de inimigos internos, seja na ação direta que os transforma em população e os criminaliza, para em seguida deslocá-los, expulsá-los, encarcerá-los ou mesmo exterminá-los como parte de procedimentos administrativos (20). Pela representação sinonímica entre a noção de democracia e os atuais regimes ocidentais ter atingido hoje validade quase absoluta, seja no senso comum, seja em boa parte da bibliografia, utilizamos a categoria "violência de Estado" para nos referirmos aos atos violentos, seja legalizados ou francamente ilegais, que se produzem como modo de sustentar uma fronteira no acesso ao "direito a ter direitos", ou seja, uma fronteira que reivindica uma clivagem, quase sempre figurada no plano da natureza, entre os que pertencem à comunidade política e por isso devem ser protegidos, daqueles que a ameaçam e devem ser combatidos. É exatamente nessa medida - a da violência de Estado - que os desaparecimentos forçados na Argentina e o assassinato de jovens favelados nas periferias de São Paulo, que estudamos nas nossas etnografias recentes, podem ser colocados em perspectiva. Inúmeras outras situaçôes nacionais contemporâneas - a começar por Estados Unidos e Europa em sua guerra ao terror, passando pela "reconstrução estatal" na América Latina e África - revelam a fabricação ativa de inimigos internos como baliza cognitiva para se pensar normativamente a ordem social.

Nessa medida, um contraste fundamental entre nossos casos se explicita. A temática do desaparecimento forçado se tornou, na Argentina, assunto político de primeira ordem e os movimentos que o denunciavam foram progressivamente se tornando vozes mais legítimas publicamente. Seus argumentos se fizeram ouvir nacional e internacionalmente, sua presença funcionou para demarcar as balizas do discurso político oficial na transição democrática e resta ainda hoje muito viva. A memória da ditadura se reconstruiu, entre familiares de vítimas, mas também entre as gerações mais recentes e os atores públicos contemporâneos, como memória de injustiça e de dor que não se pode esquecer. A criminalização, extermínio e desaparecimento de milhares de pessoas ofereceu a oportunidade para um luto coletivo, vivido como luta intensa, que foi se legitimando publicamente pouco a pouco, ainda que os movimentos jamais tenham obtido satisfação de todas as suas demandas.

No caso brasileiro contemporâneo, a violência de Estado voltada contra grupos de favelas e periferias, centrada na criminalização seletiva, tem produzido um tipo de clivagem social que se encaminha muito mais para a alteridade radical do que para a possibilidade de legitimação do discurso divergente. A tendência contemporânea não é, por exemplo, de que o discurso e as demandas de grupos no foco das estatísticas de homicídio sejam enunciados publicamente e cresçam em capacidade de legitimação pública. Por isso, toda a grade de inteligibilidade, ou seja, os critérios pelos quais se reivindica sentido para o discurso enunciado pelos sujeitos, teve de ser alterada. Em São Paulo, esses discursos foram, por exemplo, muito mais elaborados nas favelas pelos debates internos ao Primeiro Comando da Capital, uma facção criminal, do que nos debates públicos vinculados aos setores estatais responsáveis por direitos humanos ou segurança pública. As grandes medidas de controle da violência policial, ao longo dos anos 2000 , foram produzidas pelo próprio "mundo do crime" (21). Assim, as principais caixas de ressonância para a reflexão e a crítica da violência de Estado mantiveram-se num mundo progressivamente mais afeito aos próprios sujeitos criminalizados das favelas, codificado internamente entre eles, do que foram ouvidas publicamente. Mundo que, assim, foi progressivamente se autonomizando frente à grade de inteligibilidade política estatal, centrada normativamente no direito universal. Com isso, de um lado, se constituíram regimes normativos - o do "crime" é bastante evidente, conforme já demonstrou há quase duas décadas Luiz Antonio Machado da Silva (1999), que coexistem com os estatais; de outro lado, e como reação a esse processo, esses regimes passaram a alimentar o ciclo de criminalização que, justamente, os havia produzido. Essa tendência, ao contrário do que se passou na Argentina, já impede definitivamente qualquer possibilidade de legitimação política do discurso democrático contra a violência de Estado, tanto quanto a legitimação política dos atores inscritos nas tentativas de controlá-la fora dos marcos legais. Enquanto na Argentina o movimento de familiares de desaparecidos põe em relevo a identidade política das vítimas (a definição do "inimigo" teria sido diretamente "política”), no Brasil as Mães de Maio e outros coletivos de familiares de vítimas da violência policial buscam enfatizar o critério racial (negros), de classe (pobres) e territorial (periferias) da repressão perpetrada. Talvez esteja aí a chave para perceber porque os ganhos entre esses movimentos sejam tão díspares.

Dessa perspectiva, o que se poderia chamar de ação política - a construção ativa de terrenos de locução legítima em um espaço público, operada cotidianamente pelos sujeitos sociais - definitivamente não fica restrita, no caso brasileiro, às disputas entre sujeitos já constituídos (movimentos, partidos, sindicatos etc) que 
se encontram em terrenos de negociação de poder definidos em consenso (conselhos, assembleias, fóruns de participação ou representação social estatais). Essa ação potencialmente política vai se assentar, justamente, na disputa acerca da constituição desses mesmos terrenos e sujeitos: os militantes das periferias precisam primeiramente se forjar enquanto sujeitos, transpondo fronteiras impostas pela gestão e pela violência, para serem ouvidos. Os bandidos das favelas paulistas, que se reúnem para tentar impedir o aumento de homicídios de jovens nas "quebradas", jamais terão voz pública nos debates sobre esses temas. Nem seu léxico permitiria que sua voz fosse aí compreendida como fala articulada. Por não existir como tal, a mediação entre o "mundo da favela", cada vez mais criminalizado, e o mundo político instituído, já não pode se consolidar. A fronteiras que são demarcadas nas margens da política sustentam, assim, a restrição da legitimidade de grupos inteiros situados às margens da cidade. Moraliza-se de tal forma os espaços que se poderia politizar que os moradores desses territórios, ao invés de serem considerados cidadãos pela universalidade da noção de direitos, se esforçam de maneira permanente para provar que são pessoas de bem, honestas, trabalhadoras, confiáveis, pacíficas, que não possuem relação com "o tráfico".

Nesse sentido, torna-se interessante atentar para a importância de entender as particularidades da violência de Estado definida em termos "políticos", ou da violência perpetrada contra grupos definidos em termos "políticos", na medida em que as distintas formas a partir das quais as vítimas e as violências são adjetivadas podem ser reveladoras das distintas funcionalidades das práticas de gestão da vida, da morte e da ordem social, em conjunturas específicas. Se é pelo adjetivo "política" que se define a violência de Estado perpetrada durante a ditadura, é porque se entende que essa violência se dirige àqueles que, de alguma forma, ainda são reconhecidos como atores políticos em referência a uma comunidade nacional. Quando um problema político como a violência de Estado no Brasil, ao contrário, é tratado nas páginas policiais, produz-se uma "massa de inúteis do mundo" nas dimensōes internas às fronteiras nacionais que, em todas as épocas, impediu qualquer democracia substantiva. A reflexão sobre as mortes às quais fazem referência nossas etnografias, bem como sobre o luto público (ou a ausência de luto) em torno desses mortos, nos leva então a questionar, seguindo Butler (22), em que medida essa distribuição desigual da dor - que determina quais vidas contam como vidas e quais mortes são dignas de lamento público - produz e reitera certas concepçôes normativas do humano, delimitando as fronteiras de pertencimento à comunidade política e, por conseguinte, "do direito a ter direitos".

Liliana Sanjurjo é pós-doutoranda (Capes) junto ao Programa de Pós-Graduação em Antropologia Social da UFSCar e pesquisadora do Centro de Estudos de Migraçōes Internacionais (Cemi) do IFCH da Unicamp.

Gabriel Feltran é professor do Departamento de Sociologia da UFSCar, pesquisador do Centro de Estudos da Metrópole (CEM) e do Núcleo de Etnografias Urbanas do Cebrap.

\section{NOTAS E REFERÊNCIAS BIBLIOGRÁFICAS}

1. Optamos pelas grafias em itálico das expressões segurança nacional e segurança pública (poderíamos acrescentar aqui violência urbana) para enfatizar que partimos da premissa, seguindo Machado da Silva e Misse, de que não tomamos tais noções como categorias analíticas, mas sim como representações. Ou melhor, essas noções se constituem como categorias de entendimentos que conferem sentido à experiência de vida nas cidades, consolidando representações que são chave para a compreensão de práticas e relações às quais elas se referem. O intuito é preservar o vínculo entre segurança nacional e segurança pública como temas de agenda pública (como problema social em debate), por um lado, e como representação coletiva, por outro.Ver: Machado da Silva, L. A. Vida sob cerco: violência e rotina nas favelas do Rio de Janeiro. Rio de Janeiro: Faperj/Nova Fronteira. 2008; Misse, M. Crime e violência no Brasil contemporâneo: estudos de sociologia do crime e da violência urbana. Rio de Janeiro: Lumen Juris. 2006; Wacquant, L. As prisões da miséria. Rio de Janeiro: Zahar. 2011.

2. Feltran, G. S. "A gestão da morte nas periferias de São Paulo: um dispositivo entre governo e crime (1992-2011)". In: Souza Lima, A. \& García-Acosta, V. (Orgs.). Margens da violência: subsídios ao estudo do problema da violência nos contextos mexicano e brasileiro. Brasília: ABA. 2014.

3. Para uma reflexão acerca de como categorias sociais, políticas e administrativas (tais como "favelados" e "refugiados") geram processos de distinção e hierarquização, materializando processos de produção de desigualdades diversas por meio de expedientes administrativos do Estado, ver neste Núcleo Temático da revista Ciência e Cultura o trabalho de Vianna e Facundo.

4. Ver: Butler, J. Vida precaria: el poder del duelo y la violencia.Buenos Aires: Paidós. 2006; Butler, J. Marcos de guerra. Las vidas Iloradas. Buenos Aires: Paidós. 2010.

5. O artigo é resultado de trabalhos de campo realizados pelos autores na Argentina e no Brasil, entre 2004 e 2014, que resultaram nas seguintes teses: Feltran, G. S. Fronteiras de tensão: política e violência nas periferias de São Paulo.São Paulo: Editora Unesp/CEM-Cebrap. 2011; Sanjurjo, L. "Sangue, identidade e verdade: memórias sobre o passado ditatorial na Argentina". Tese (doutorado em antropologia social) - PPGAS, Universidade Estadual de Campinas. 2013. As pesquisas foram financiadas pelo CNPq e Fapesp, respectivamente.

6. Declaração do capitão da marinha Jorge Acosta durante audiência judicial da Causa ESMA, em 20 de outubro de 2011, no Tribunal Federal de Buenos Aires. Acosta (condinome "Tigre") integrou o Grupo de Tarea 33.2 da Escuela Mecánica de la Armada (ESMA), um dos principais centros clandestinos de detenção, tortura e extermínio em funcionamento durante a ditadura militar argentina.

7. Filc, J. Entre el parentesco y la política: familia y dictadura 1976-1983. Buenos Aires: Biblos. 1997.

8. Crenzel, E. La historia política del nunca más. La memoria de los desaparecidos en la Argentina.Buenos Aires: Siglo Veintiuno Editores. 2008. 
9. Calveiro, P. Poder y desaparición. Los campos de concentración en Argentina.Buenos Aires: Colihue. pp. 143. 2008.

10. Schindel, E. “Las ciudades y el olvido".In:Puentes. La Plata, Ano 2, No. 7, p. 30. julho de 2002.

11. O desaparecimento forçado de pessoas pode ser entendido aqui a partir da noção de evento crítico de Veena Das: Das, V. Critical Events. An anthropological perspective on contemporary India.New Dheli/ Oxford: Oxford University Press. 1995.

12. Para uma análise que trata das disputas em torno dos sentidos da categoria desaparecidos, ver: Vecchioli, v. "Políticas de la memoria y formas de clasificación social. Quiénes son las víctimas del terrorismo de Estado en la Argentina?". In: Groppo, B. \& Flier, P. (Orgs.). La imposibilidad del olvido: recorridos de la memoria en Argentina, Chile y Uruguay.La Plata: Ediciones Al Margen. 2001.

13. Para uma discussão sobre a despolitização do relato sobre a ditadura argentina no período de transição democrática, ver: Crenzel, E, op. cit. 2008; Feld, C. Del estrado a la pantalla: las imágenes del juicio a Ios ex comandantes e Argentina.Madrid: Siglo XXI de España Editores. 2002; Jelin, E. "La justicia después del juicio: legados y desafíos en la Argentina postdictatorial". In:Fico, C., Ferreira, M. \& Quadrat, S. (Orgs.). Ditadura e democracia na América Latina: balanço histórico e perspectivas. Rio de Janeiro: Editora FGV. 2008.

14. Foucault. A verdade e as formas jurídicas. Rio de Janeiro: Nau Editora. 1996.

15. A expressão "violência política" se refere, usualmente, a um tipo específico de uso da força dirigido àqueles indivíduos que portam conjuntos de valores, crenças ou projetos políticos contrários ao programa político oficial, ou dominante. Em regimes autoritários a violência política é computada entre as formas de exercício legítimo da força, nos Estados democráticos ela é sempre ilegal. Essa violência tenta manter fora da arena pública não apenas o sujeito a quem se dirige, mas também aqueles os quais suas palavras representariam. Esta modalidade violenta se diferencia de outras formas de uso da força, por ser centralmente dirigida à locução política, às palavras, e não apenas aos corpos dos indivíduos que a sofrem (matá-los tem por função estrita silenciá-los).

16. Feltran, G.S. "Margens da política, fronteiras da violência: uma ação coletiva das periferias de São Paulo". In: Lua Nova, 79. 2010; Feltran, G.S. "The management of violence on the periphery of São Paulo: a normative apparatus repertoire in the PCC era". In: Vibrant, 7. 2010; Feltran, G.S. "Governo que produz crime, crime que produz governo. O dispositivo de gestão do homicídio em São Paulo (1992-2011)". In: Revista Brasileira de Segurança Pública, 6. 2012.

17. Ver: Biondi, K. Junto e misturado: uma etnografia do PCC. São Paulo: Terceiro Nome/Fapesp. 2010. Biondi, K. e Marques, A. J. “Memória e história em dois comandos prisionais". In: Lua Nova, 79. 2010; Dias, C.C.N. "Da pulverização ao monopólio da violência: expansão e consolidação da dominação do PCC no sistema carcerário paulista". Tese (doutorado em sociologia). Programa de Pós-Graduação em Sociologia. Universidade de São Paulo. 2011; Hirata, D.V. “Sobreviver na adversidade: entre o mercado e a vida". Tese (doutorado em sociologia). Programa de Pós-Graduação em Sociologia. Universidade de São Paulo. 2010.

18. Machado da Silva, L.A. "Criminalidade violenta: por uma nova perspectiva de análise". In: Revista de Sociologia e Política, 13.1999.

19. Críticas ao potencial democrático da democracia liberal, baseadas na sua dependência da forma empresa, já foram enunciadas em: Lindblom, C. E. Política e mercados: os sistemas políticos e econômicos do mundo. Rio de Janeiro: Zahar Editores. 1979. Feltran, op. cit.

20. Araújo, F. “Das consequências da 'arte' macabra de fazer desaparecer corpos: violência, sofrimento e política entre familiares de vítima de desaparecimento forçado". Tese de doutorado. PPGAS/IFCS/UFRJ. 2012; Vianna, A. e Farias, J. "A guerra das mães: dor e política em situações de violência institucional". In: Cadernos Pagu, 37. 2011; Hirata, D.V. op. cit. 2010.

21. Feltran, G.S, op. cit. 2012.

22. Butler, J., op. cit. 2006. 